\title{
Pathogenic Activity of Methicillin-Resistant Staphylococcus aureus Strains Isolated from Colorectal Cancer Patients
}

\author{
Shorena $^{1}$ Khetsuriani $^{2}$, Khatuna Pochkhua, Maia Zarnadze ${ }^{3}$ \\ ${ }^{1}$ Tbilisi State Medical University, Tbilisi, Georgia \\ ${ }^{2}$ St. Andrew the First-Called Georgian University of the Patriarchate of Georgia, \\ ${ }^{3}$ PetreShotadze Medical Academy, Tbilisi, Georgia
}

\begin{abstract}
There were studied pathogenic activity of methicillin-resistant Staphylococcusaureus (MRSA) strains isolated from color ectal cancer patients and were compared to non-MRSA strains isolated from patients with intestinal dysbiosis. The aim of study was to determine changes of biological properties of this important bacterium depend on the severity of disease. Study revealed that MRSA strains are widespread in patients with colorectal cancer. MRSA strains revealed higher pathogenic activity than non-MRSAstrains. Some determinants of pathogenicity (urease, lecithinase production, hemolysis, proteolysis), also carbohydrate and mannitol fermentations in aerobic and anaerobic conditions are characterized with high activity in MRSA strains in comparison of non-MRSA strains. Coagulase- and catalase-positive were all strains from both groups.
\end{abstract}

Keywords: MRSA, colorectal cancer, S. aureus, pathogenic factors, enzymes, carbohydrate fermentation

\section{Introduction}

More than 100 trillion microorganisms live in the human intestine. They play an important role in health status and diseases, including cancer. Specific bacteria and gastrointestinal dysbiosis can potentiate the development and progression of gastrointestinal neoplasms by destroying DNA, activating oncogenic signaling pathways, producing metabolites that promote the development of tumors and suppressing antitumor immunity [8].

Changes in the interactions among the intestinal epithelial cells, intestinal microflora, and host immune system are associated with many diseases, including cancer [10].

Colorectal cancer represents an important disease as one of the major causes of death worldwide. Besides of many factors (diet, family history, age, ethnicity, others), metabolic products of intestinal microflora also influence and predispose to the development of colorectal cancer [9].

Staphylococcus aureus, although identified as a commensal, is also a common cause of human bacterial infections [4]. Colonization of the gastrointestinal system by $S$. aureus strains in hospitalized patients may lead to important clinical implications[4] and is able to acquire resistance to a variety of antibiotics[1,6].

In addition to its ability to outwit human immune system, its multi-drug resistance phenotype, particularly - in methicillin-resistant $S$. aureus (MRSA) strains makes it one of the most intractable pathogenic bacteria in the history of antibiotic chemotherapy [5,7].

Based on the above mentioned reasons we studied the activity of pathogenic factors of $S$. aureus isolated from colorectal cancerpatientsin comparison with the same bacteria isolated from non-cancer patients to determine how change biological properties of this important bacterium can depend on the severity of disease.

\section{Materials and Methods}

There were studied64S. aureusstrains. Sample materials feaces -were taken from patients with colorectal cancer(36strains -I group) and from patients with intestinal dysbiosis (28 strains - control, II group). Samples were collected before surgical involvementsor administration of therapeutic regimes.Cultivation of $S$. aureus were performed on 5\% blood agar, egg yolk-salt agar, meat-peptone agar, meat-peptone broth, milk-salt agar of Eikman; Biochemical properties have been analyzed on results of carbohydrate fermentation in aerobicand anaerobic conditions; carotenoid pigment formation was tested on $37^{\circ} \mathrm{C}$ for 24 hours in milksalt agar.Catalase activity was tested by using of hydrogen peroxide, hemolysis - on 5\% blood agar, hemolytic zones around the colonies indicated positive results). Lecithinase activity was determined by egg-yolk saline medium. Turbidity around the colony with rainbow-like corona indicated positive result, coagulase (was demonstrated by mixing bacteria with blood plasma on a slide; in positive cases occurred clumping with fibrin formation), also were determined urease, proteolytic activities and novobioc insusceptibility tests [2].

Growth characteristics of cultivation were studied in meatpeptone broth. Equal turbidity in broth was one of the indicators of typical strains. Aerobic fermentation of carbohydrate determination was tested by using of $1 \%$ Peptone-Water (with glucose, mannitol, sucrose or lactose) in addition of $2 \mathrm{ml}$ Andrade reagent. After the incubation, the red color of medium indicated on carbohydrate fermentation. Bacterialculture was transferred in2\% peptonsolution for 


\section{International Journal of Science and Research (IJSR) \\ ISSN (Online): 2319-7064 \\ Index Copernicus Value (2016): 79.57 | Impact Factor (2015): 6.391}

proteolytic activity. Additionaltest for $S$. aureus identification was novobiocin sensitivity (MIC- $2 \mathrm{mg} / \mathrm{ml}$ ).

\section{Results}

MRSA strains were discharged in both groups $66.66 \pm 7.86 \%$ (I group) and $28.57 \pm 8.53 \%$ (II group). According of these data, non-MRSA strains were isolated in low frequency - I group - $33.33 \pm 7.85 \%$, II group $28.57 \pm 8.53 \%$ cases (Table N1).

Distribution of MRSA and non-MRSA strains in patients Table N1

\begin{tabular}{|c|c|c|c|c|}
\hline \multirow{2}{*}{ S. aureus strains } & \multicolumn{2}{|c|}{ I group $(\mathrm{n}=36)$} & \multicolumn{2}{c|}{ II group $(\mathrm{n}=28)$} \\
\cline { 2 - 5 } & Abs. & $\%$ & Abs. & $\%$ \\
\hline MRSA & 24 & $66.66 \pm 7.86$ & 8 & $28.57 \pm 8.53$ \\
\hline Non-MRSA & 12 & $33.33 \pm 7.85$ & 20 & $71.42 \pm 8.53$ \\
\hline
\end{tabular}

Also were studied and compared pathogenic factors of MRSA and non-MRSA strains (table N2). As in table shownall strains were plasma coagulase- and catalasepositivein both groups. Ability of carbohydrate fermentation in anaerobic condition was higher in I group $(83.33 \pm 7.6 \%$ vs. $75.00 \pm 12 \%)$.

Some pathogenicityfactors of S. aureus

Table N2

\begin{tabular}{|c|c|c|c|c|c|}
\hline \multirow{2}{*}{$№$} & Identity markers & \multicolumn{2}{|c|}{$\begin{array}{c}\text { MRSA strains } \\
\mathrm{n}=24\end{array}$} & \multicolumn{2}{|c|}{$\begin{array}{c}\text { Non-MRSA } \\
\text { strains } \\
\mathrm{n}=12\end{array}$} \\
\cline { 3 - 6 } & $\mathrm{abs}$ & $\%$ & $\mathrm{abs}$ & $\%$ \\
\hline 1 & Plasma coagulase-positive & 24 & 100 & 12 & 100 \\
\hline 2 & Catalase-positive & 24 & 100 & 12 & 100 \\
\hline 3 & Urease -positive & 21 & $87.50 \pm 6.75$ & 6 & $50.00 \pm 14.43$ \\
\hline 4 & $\begin{array}{c}\text { Hemolytic activity } \\
\text { (hemolysis) }\end{array}$ & 24 & 100 & 9 & $75.00 \pm 12.50$ \\
\hline 5 & Lecithinase activity & 22 & $91.66 \pm 5.66$ & 9 & $75.00 \pm 12.50$ \\
\hline 6 & $\begin{array}{c}\text { Proteolytic activity } \\
\text { (production of } \mathrm{H}_{2} \text { S) }\end{array}$ & 22 & $91.66 \pm 5.66$ & 8 & $66.66 \pm 13.60$ \\
\hline 7 & $\begin{array}{c}\text { Mannitol fermentation in } \\
\text { anaerobic conditions }\end{array}$ & 20 & $83.33 \pm 7.61$ & 7 & $58.33 \pm 14.23$ \\
\hline 8 & $\begin{array}{c}\text { Carbohydrate (glucose, } \\
\text { mannitol, lactose, } \\
\text { saccharose) fermentation } \\
\text { in aerobic conditions }\end{array}$ & 23 & $83.33 \pm 7.61$ & 9 & $75.00 \pm 12.50$ \\
\hline
\end{tabular}

Hemolytic activity revealed in all MRSA strains in comparison of non-MRSA strains $(75.00 \pm 12.50 \%)$. Proteolytic (production of $\mathrm{H}_{2} \mathrm{~S}$ ) and lecithinase activities were same in I group - 91.66 $\pm 5.66 \%$; these enzymes revealed more low activity in II group $(75.00 \pm 12.50 \%$ and $66.66 \pm 13.60 \%$ - respectively). Mannitol fermentation in anaerobic condition was much higher in I group $83.33 \pm 7.61 \%$ than in II group $-58.33 \pm 14.23 \%$.

\section{Conclusions}

1) MRSA strains are widespread in patients with colorectal cancer.

2) Some determinants of pathogenicity (urease, lecithinase production,hemolysis, proteolysis), also carbohydrate and mannitol fermentations in aerobic and anaerobic conditions are characterized with high activity in
MRSA strains in comparison of non-MRSA strains. Coagulase- and catalase-positive were all strains from both groups.

3) MRSA strains revealed higher pathogenic activity than non-MRSAstrains.

\section{References}

[1] Assis LM, Nedeljković M, Dessen A. New strategies for targeting and treatment of multi-drug resistant Staphylococcus aureus. Drug Resist Updat. 2017 Mar; 31:1-14.

[2] Baron E.,lance R. et all Diagnostic Microbiology. 1994 by Mosby-Year book inc.

[3] Bhalla A., Aron A.C.,DonskeyD.J.Staphylococcus aureus intestinal colonization is associated with increased frequency of $S$. aureus on skin of hospitalized patientsand is able to acquire resistance to a variety of antibiotics. BMC Infect Dis. 2007; 7: 105

[4] David MZ, Daum RS. Treatment of Staphylococcus aureus Infections.Curr Top MicrobiolImmunol. 2017 Sep 13. doi: 10.1007/82_2017_42

[5] Hanberger H. et al. increased mortality associated with methicilin-resistant Staphylococus aureus (MRSA) infection in the intensive Care Unit: results from the EPIC II study. International Journal of Antimicrobial,2011 DoL:10.1016/j.

[6] Hassoun A, Linden PK, Friedman B. Incidence, prevalence, and management of MRSA bacteremia across patient populations-a review of recent developments in MRSA management and treatment.Crit. Care. 2017 Aug 14;21(1):211.

[7] Hiramatsu K, Katayama Y. et al. Multi-drug-resistant Staphylococcus aureus and future chemotherapy.J Infect Chemother. 2014 Oct; 20(10):593-601.

[8] Mima K., Ogino S., Nakagawa S., Sawayama H., et al. The role of intestinal bacteria in the development and progression of gastrointestinal tract neoplasms. SurgOncol. 2017 Dec;26(4):368-376. doi: 10.1016/j.suronc.2017.07.011.

[9] Roberta M. Manzat-SaplacanPetru A.,Balacescu M. et al Can we change our microbiome to prevent colorectal cancer development? ActaOncologica. 2015. Vol. 54, issue 8

[10]Zitvogel L., Galluzzi L., Viaud S.,et al. Cancer and the gut microbiota: An unexpected link.SciTransl Med. 2015 Jan 21; 7(271): 271.

\section{Volume 6 Issue 12, December 2017}

